This item was submitted to Loughborough's Research Repository by the author.

Items in Figshare are protected by copyright, with all rights reserved, unless otherwise indicated.

\title{
Managing capability knowledge across the extended enterprise
}

PLEASE CITE THE PUBLISHED VERSION

http://dx.doi.org/10.1109/SYSOSE.2010.5544071

PUBLISHER

(c) IEEE

VERSION

VoR (Version of Record)

LICENCE

CC BY-NC-ND 4.0

REPOSITORY RECORD

Pilfold, Sofia Ahlberg, and Michael Henshaw. 2019. "Managing Capability Knowledge Across the Extended Enterprise". figshare. https://hdl.handle.net/2134/7226. 
This item was submitted to Loughborough's Institutional Repository (https://dspace.lboro.ac.uk/) by the author and is made available under the following Creative Commons Licence conditions.

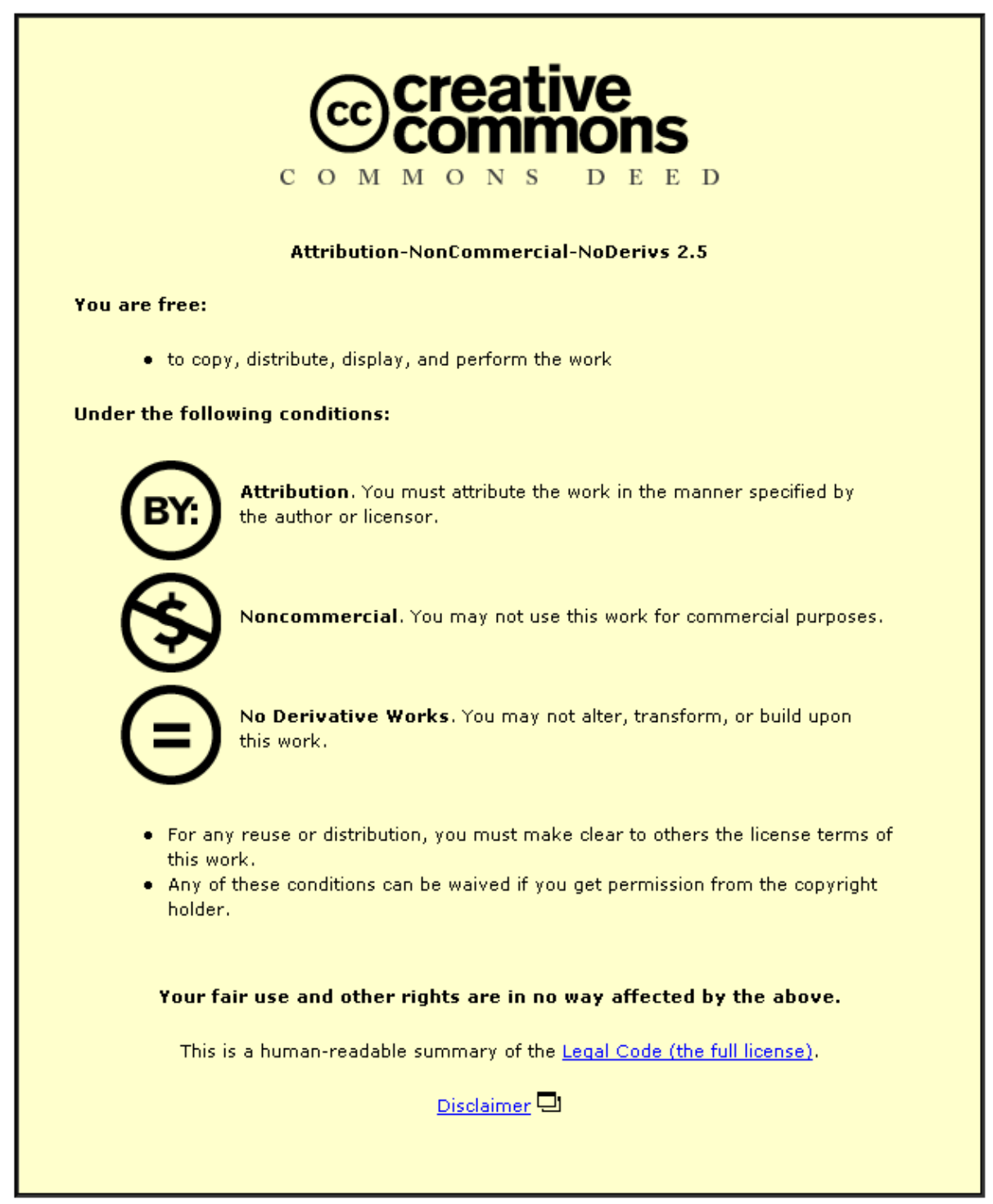

For the full text of this licence, please go to: http://creativecommons.org/licenses/by-nc-nd/2.5/ 


\title{
Managing Capability Knowledge Across the Extended Enterprise
}

\author{
Sofia Ahlberg Pilfold and Michael Henshaw \\ Engineering SoS Group, Loughborough University \\ Loughborough, Leicestershire, LE11 3TU, UK \\ $\{$ k.s.ahlberg-pilfold $\{$ mjd.henshaw\}@lboro.ac.uk
}

\begin{abstract}
The Through Life Capability Management (TLCM) construct, currently being embraced by defense departments across the globe, is a commercial and social endeavor that requires a multitude of socio-technical systems to work together effectively in a system of systems. TLCM demands changes in the organization and culture of the defense supply chain in ways that fly in the face of traditional commercial wisdom. This paper reports on an on going enterprise model that is being created as part of a wider research project into the management and sharing of knowledge across the TLCM enterprise. The model describes the UK MoD TLCM enterprise as a set of responsibilities that agents execute by accessing identified resources, in this instance limited to information and knowledge. Preliminary results indicate changes in the structure of the supply chain organization that raises significant challenges in the areas of decision making, knowledge sharing, organizational learning, culture and behavior.
\end{abstract}

Keywords: Decision making, distributed knowledge systems knowledge management, knowledge sharing, ORDIT, systems of systems, through life capability management, TLCM

\section{Introduction}

Since 2005 the British Ministry of Defense (UK MoD) has been in the process of adapting a Through Life Capability Management (TLCM) approach to acquisition and to make an increasing number of the roles and processes traditionally carried out by the armed forces themselves available for industry to deliver through partnership arrangements [1]. This initiative reflects a trend in the industrial sector for suppliers and manufacturers to move away from selling only product commodities and, instead, to offer a mix of products and services where the supplier gives through-life support for the product or, system of products, for its customers [2] [3] [4] [5] [6]. Alternatively, companies offer customers use of an asset with an agreed and guaranteed availability, often in the form of so-called "service level agreements" [4] [7].

This product-service approach results in a defense supply chain that is highly integrated and that sets major challenges to the engineering and commercial activities in acquisition projects. If TLCM is to deliver the benefits that are sought, it is not only the processes and organizational structures that need to be changed. The behaviors of customers and suppliers must change as well [9] [10]. Knowledge of systems must be managed effectively over the extended enterprise including customer, prime contractors, and other suppliers and over periods of many years, in some cases, even several decades. Participation in the enterprise demands that organizations on both sides share information and knowledge that they have traditionally kept to themselves.

This paper describes a modeling exercise of the TLCM enterprise that was conducted as part of a greater research project which focuses on how the product service shift affects the way in which the organizations within the TLCM enterprise manage and share knowledge and information.

\section{TLCM and Managing Knowledge}

In the vocabulary of the British MoD, capability (the ability to achieve a desired military outcome) is made up of Force Elements at Readiness (FE@R) which are the various components of military force that are ready for deployment at a particular time and may be combined to provide the required force, and the eight Defense Lines of Development (DLoDs), which must all be developed appropriately in order for capability to be realized [11]. The DLoDs are: training, equipment, personnel, information, doctrine and concepts, organization, infrastructure, and logistics. Interoperability is sometimes included as a ninth DLoD.

In our view, the output of TLCM is not capability or FEs@R. After all, industry and the armed forces have always delivered, managed and operated capabilities in the form of equipment platforms, services and personnel in one form or another and more or less successfully. If the capability is the output, then the skeptics of TLCM, both in industry and within the MoD, are correct when they argue that this is what they are already doing and have been doing for years. Instead, we see TLCM as the overarching principle that directs how the processes in acquisition are organized, managed and performed. TLCM is the process or framework that manages capability through life. Hence the output of TLCM is the improved management of capability. This is an important point to make because from 
this perspective, we are separating the technical aspects of creating, delivering, operating and disposing of the systems of systems that make up capabilities from the management processes that support the creation, delivery, operation and disposal of the capabilities and which may be regarded as a complex system of systems in its own right.

The TLCM extended enterprise can be viewed as a system of systems problem. Since the MoD has increased the number of defense support activities available to industry for commercial exploitation and adopted a more integrated supply chain, the enterprise that is the defense supply chain has become more complex. Interactions and feedback loops have become richer and greater in number as the organizations involved have a larger set of connections to each other. To a large extent, these interactions are made up of information or knowledge exchanges. The increased number of interactions induces complexity in its own right, but this is aggravated by legacy behaviors that mean that some connections work while others do not, resulting in information in some cases becoming partial. There are also many simultaneous nonlinear interactions, which means that it is not possible to keep track of causal relationships between the organizations [12].

A military organization is a hierarchical organization. But complex systems do not do well with strictly hierarchical structures [12]. Hierarchies are typically viewed as tidy nested structures with clear lines of communication. In complex systems, this clarity however may only exist on paper as, in reality, the interactions need to cut across hierarchical levels and also between different hierarchies [13]. In a complex system, the many interdependencies between the elements of the system makes it also very difficult to determine, beforehand, what information and knowledge is needed by whom and when. Forcing interactions to flow within a rigid structure may therefore end up being detrimental to the enterprise as a whole. This is not equivalent to saying complex systems are structure-less or chaotic but that the structures found are the results of the patterns of interactions that exist between the system's elements, some of which are long-term and stable while others are transient and unpredictable [12].

Another reason why complex systems and hierarchical structures do not work well together is because the number and the non-linearity of the interactions also has implications for control within and of the system. Hayek [14] stated that planners in society do not possess all the knowledge available when conducting their work because knowledge is distributed throughout society. This results in planners not knowing what knowledge is available nor what additional knowledge they need because they are removed from the places where practical work is performed and the associated knowledge is held. Hayek also asserted that theoretical knowledge is in general more highly regarded than practical knowledge; and because planners tended to be highly educated, they also tended not to understand or be aware of the importance of the context dependant nature of knowledge relating to how and when things are best done. The status of theoretical vs. practical might have shifted somewhat since Hayek wrote his article in 1949 , but his main point about knowledge being distributed is still valid. Focusing control in one or two places increases the gap between decision making and knowledge, as decisions are taken away from the context in which the knowledge that could inform them is hosted, created and understood. It also increases the probability of important knowledge not entering the decision process at all because its existence is not known by the decision makers or because its importance is not understood.

Focusing control also forces decision makers to handle more transactions than they are realistically able to handle.. Turnbull discusses humans' limited ability to process (receive, store, process and transmit) information which if unchecked, results in information overload [15]. Creating hierarchies is seen as a way of limiting the number of transactions that each individual involved needs to process, but the strategy has major weaknesses associated with information being condensed as it moves up the hierarchical structure. The decisions made in this context are therefore not independent because the information they are based on has been shaped by how subordinates have assessed its value and importance. The rich interactions and direct and indirect feedback loops between elements means that control is better handled distributed across the system where the knowledge is held.

A systems perspective may also have implications for how the nature of knowledge is perceived. Classical knowledge management theory often defines knowledge as a hierarchy consisting of data (discrete and objective facts about events), information (data that has been sorted and analyzed to give meaning), knowledge (information linked with its potential application) [16] [17] [18] [19], and wisdom (knowledge that has an ethical perspective obtained through combination with perception and experience)[20]. From a systems' perspective, if knowledge is part of the transactions within a complex system then knowledge does not come into being outside of those interactions [12]. Knowledge is not something subjective that humans have but something that is created in our dealings with others. This also means that knowledge cannot be broken down into discreet objective facts as these are meaningless without interpretation which occurs within interactions to become knowledge.

The study of management of knowledge in organizations takes a different view on where and how knowledge is hosted and created, although it recognizes the role of interactions in knowledge creation, learning and innovation [22] [23]. Nonaka [22] builds on Polanyi's [24] concepts of tacit (knowledge held in people's heads) and explicit knowledge (knowledge that is recorded or has 
taken physical form in some way) to create a model with four different types of knowledge transformation that leads to the invention of new knowledge and innovation. Tsoukas' [23] work on firms as "distributed knowledge systems" offers a social constructivist approach to knowledge and knowledge management. This perspective holds that knowledge is not "given" to any individual or team in its entirety. Individuals have knowledge in the form of experience but knowledge is also constructed through discussion, communication and the patterns of interactions between the individuals involved.

\begin{tabular}{|l|l|}
\hline embrained & $\begin{array}{l}\text { knowledge that is reliant on cognitive } \\
\text { competence and conceptual abilities }\end{array}$ \\
\hline embodied & $\begin{array}{l}\text { knowledge that is oriented towards action, } \\
\text { "know how" }\end{array}$ \\
\hline encultured & $\begin{array}{l}\text { socially constructed knowledge that is } \\
\text { manifested in a shared understanding }\end{array}$ \\
\hline embedded & $\begin{array}{l}\text { knowledge that is set in general routines } \\
\text { encoded } \\
\text { formats such as books, manuals, handbooks, } \\
\text { etc }\end{array}$ \\
\hline
\end{tabular}

Table 1. Blacker's five knowledge categories [24].

Blackler [24] has identified five images of knowledge that can be identified in the literature about organizational learning. Building on Collins' [25] work, he summarizes the knowledge types discussed into categories of being embrained, embodied, encultured, embedded, or encoded. The conclusion Blackler draws is that all workers and organizations, irrespective of what they do, are knowledgeable and that management of knowledge must consider an array of issues that are very complex in themselves.

\section{The TLCM Enterprise Model}

The purpose of this study is to comprehend how stakeholders within UK MoD and industry understand the TLCM concept and interpret its implications for relationships between organizations in the overall enterprise. A TLCM enterprise model is derived, below, to address this question; the aim is to answer, at least in part, the following questions:

- Who/what are the elements of the TLCM enterprise?

- What are interrelationships between the elements?

- What is the organizational structure?
The implementation of TLCM is still in its infancy. At present, it is only the capability planning phase that is fully operational within the UK MoD. The delivery phase is in the process being implemented as projects progress. The enterprise is in transition and individuals and teams involved, both within the MoD and in industry are working towards understanding what this new paradigm involves for them and their respective organizations. For this reason, this work has focused mainly on the MoD side in the TLCM enterprise.

\subsection{Method}

The TLCM enterprise was modeled using the modeling language in the Organizational Requirements Definition of Information Technology Systems (ORDIT) methodology [26] [27]. ORDIT was developed in the European Union ESPRIT research and development program to assist stakeholders in defining IT systems to support their business processes. The methodology enables key users to define and discuss how they wish to develop the organization's business processes and to consider a range of potential futures before deciding on a solution. ORDIT models the enterprise as a network of responsibilities performed by agents using identified resources, see Fig. 1 below. Models can be created to the level of detail that is meaningful for the business area that is being studied. For the purpose of this research, the modeled resources have been limited to encompass data, information and knowledge.

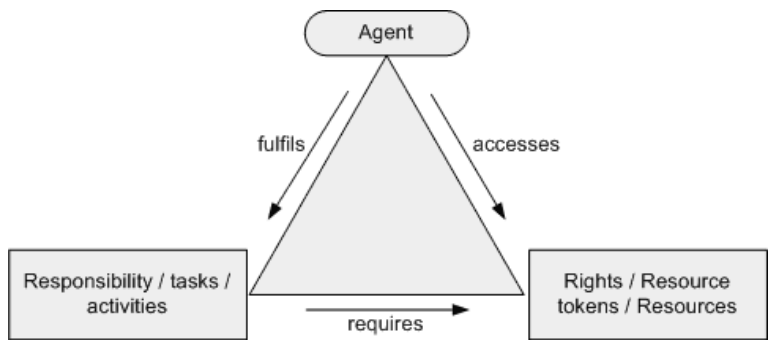

Fig. 1. The basic components of the ORDIT modeling language. (Adapted from [7].)

ORDIT identifies three different types of relationships between agents: power relationships, functional relationships, which we have interpreted as hand-over relationships or relationships where elements share or provide knowledge or information to other elements in order for them to perform their task, and customer/supplier relationships. For the purposes of this model, we have added a fourth relationship, competitors, since, within TLCM, commercial organizations can be both partners, prime- and sub-contractors, and competitors to each other at the same time, albeit in different projects. 


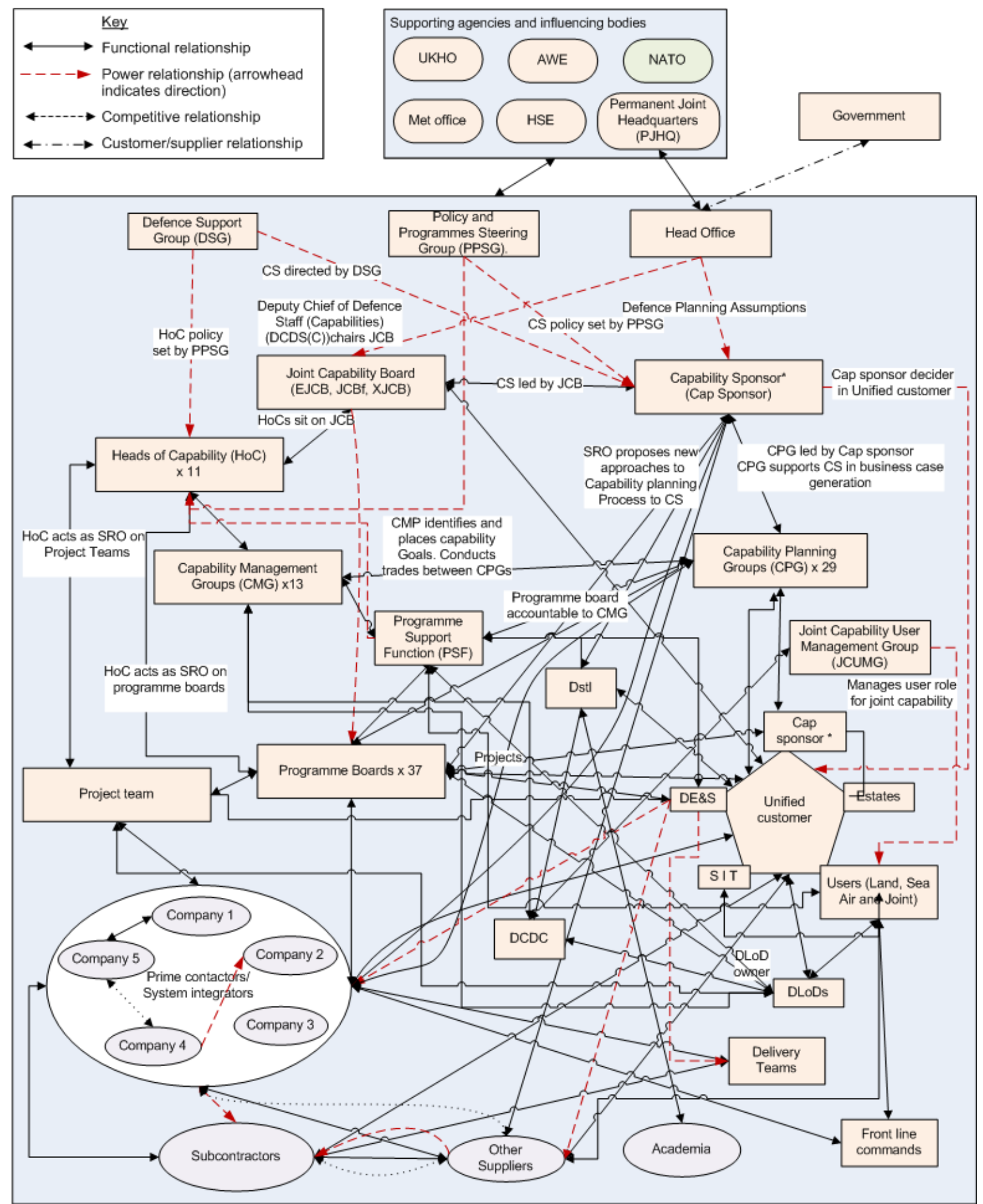

For clarity, the model does not include element boxes for all 11 Heads of Capability, 13 Capability Management Groups, 29 Capability Planning Groups nor the 37 Programme boards. The interactions between the Prime contractors/system integrators have been rationalised to represent the three different types of relationship that can exist between them at the same time: partners, customer supplier, and direct competitors. Note that the Capability Sponsor is the deciding member of the Unified Customer.

Fig. 2 Preliminary TLCM enterprise model 


\subsection{Procedure}

Information gathering for the model has come from three main sources: the UK MoD Acquisition Operational Framework website [28], the Through Life Capability Management - Practitioners course held by the UK Defense Academy, and discussions with people that are involved with the development of TLCM in industry, academia and the MoD.

We identified the main agents in the enterprise and created for each a triangle diagram with the name of the agent, its responsibilities/activities/tasks and the information and knowledge resources used to execute it .

Using Microsoft Office Visio 2007 a model for the enterprise was created by entering the agents and adding the relationships between them.

The discussions with MoD and industry staff and academics working directly with TLCM and its implementation provided helpful feedback about the correctness of the modeled relationships. These discussions and attendance on the course also provided richness to the information gathered from document sources and gave valuable insights into the challenges faced by the organizations involved, as they undergo the paradigm shift and people's reactions to and understanding of the TLCM concept.

\subsection{Results}

The preliminary results of the TLCM enterprise model is shown in Fig. 2. With the exception of the unified customer, which is a pentagon, the UK MoD elements are depicted as squares while non-MoD elements are depicted as ovals.

\subsubsection{Description of the TLCM enterprise model}

The Capability Sponsor (Cap Sponsor) is the body within the UK MoD that is responsible for leading the capability change planning process, identifying equipment and support requirements, and for identifying the optimum mixes of platforms, force enablers and force elements, referred to as force groupings, for each military capability. The Cap Sponsor is led by the Joint Capabilities Board (JCB) which uses the Defense Planning Assumptions, created by Head Office, and Future Capabilities Requirements to create a Capability Plan that governs the Cap Sponsor's activities. Sitting on the JCB are the Deputy Defense Chief of Staff (Capability), the director for equipment resources, the director for science and technology strategy, the directors of battle space maneuver, precision attack and information superiority, the head of equipment capability secretariat and eleven Heads of Capability (HoCs). Each of the HoCs is responsible for an area of capability, for which they define the requirements and identify "equipment-based options that are coherent across all DLoDs" [11]. The HoCs chair one or more Capability Management Groups (CMG), that support them in managing their respective capability areas. The CMGs are responsible for setting capability priorities and to carry out trades between projects within and between their respective capability areas.

In the Capability Planning Groups (CPG), the MoD unified customer with representatives from the five stakeholders within the MoD community including the Cap Sponsor (deciding member), users, Defense Estates, Defense Equipment and Support (DE\&S) and Science, Innovation and Technology (S I T), are responsible for developing cross-DLoD solutions to the force groupings decided by the Cap Sponsor. The CPG also sets up program boards for projects that span multiple DLoDs. The program boards handle one or more projects each. The HoCs act as Senior Responsible Owners (SROs) for their respective program boards and project teams. Contracts with are placed with industry via DE\&S.

The TLCM concept involves the MoD and industry working together in partnership, to the point where industry and MoD personnel work together as one integrated organization. For this reason, engagement with industry should start early, beginning at the capability planning phase in order to provide valuable input concerning aspects such as technical maturity, industrial threats and opportunities, export considerations and cost. As capability planning progresses to the awarding of contracts to industry in the capability generation phase and further into capability operation and eventual termination and disposal phases, the relationships and interdependencies between the $\mathrm{MoD}$ and industry continue and develop. This results in the boundaries between the roles of the industry and the MoD in the enterprise becoming blurred. The emphasis on capability rather than equipment or systems also shifts the emphasis on the end-user away from that as the customer and towards that as part of the capability being sought. Consequently, from a systems perspective the role of the customer falls on the body that orders the military capability to be used, i.e. the government, with the MoD and industry together acting as the supplier.

\subsubsection{Interactions}

For the sake of clarity, the diagram does not include separate boxes for all the HoCs, CMGs, CPGs and program boards and so it does not reflect any interactions between these different organizational elements. However, these interactions do exist and they are many in number. They are predominantly functional in nature reflecting the need for the different bodies involved in TLCM planning to share information and knowledge across capability areas and programs. The intensity of interactions is not unproblematic however. These relationships can be modeled should they need arise to analyze them further. On the training course delegates heard examples of how CPGs 
struggle with having to attend and monitor developments discussed in more meetings held by other CPGs than there are personnel available to attend them. This leads CPGs, to decide which meetings are the most important for them to attend, respectively, and to monitor the rest remotely via telephone, in the hope that, if they need to interface with a CPG whose meetings they are not attending, that someone from this other CPG will contact them to get them involved. The need to adopt this method of working was confirmed by delegates involved with TLCM from across the MoD.

Course delegates and interviewees raised concerns about the effects of causal interactions between projects as the interdependencies of projects become difficult to get an overview of, especially when they encompass several DLoDs. This may be relatively "easy" during the planning stage but may be much more difficult to keep sight of when programs are up and running and, for example, there are calls for changes in the specifications. The domino-effect of any approved changes may not only change how the DLoDs are developed in relation to each other, but also the time at which outputs, whether material or not, are delivered. This in turn will affect any project that is dependant on those outputs in order to function properly.

\subsubsection{Control and Structures}

Control of acquisition within the MoD is centralized in one body, the Capability Sponsor, who makes decisions relating to new equipment and equipment support and to whom the delivery teams and program boards are accountable. In discussions during the course, comments were made about the large number of reports that are created for the HoCs sitting in the Cap Sponsor in order to inform their decisions and the vast amount of information that they need understand and "keep in their heads".

Although the structures of the MoD TLCM organization appear to be hierarchical, the comments about the information overload on decision makers in the system may indicate that, although the top level officers have the power to decide, the experts in the organization have a significant influence on the decisions made. We need to study this further to understand these relationships. However, even if the acquisition organization within the $\mathrm{MoD}$ is adopting a integrated approach and structure, it is surrounded by and interacting with an organization that is very hierarchical. Comments have been made that the cross-DLoD and tri-service approach to capability planning, generation and operation in TLCM is not consistent with the work of core business management functions such as career progression planning, and distribution of competencies and training which are single service based.

Observers in industry and academia of the implementation of TLCM comment on how planning and management is driven by a view of capability as being based around equipment platforms and that can be seen in how capabilities are grouped into capability areas in a way that reflects a "stovepipe" approach to management.

\subsubsection{Processes, behaviors and people}

As mentioned above, beyond the capability planning phase, the processes to support TLCM are still being developed. Consequently there is, as yet, no set process for how "to do" TLCM. Instead, emphasis is put on the need to adopt behaviors that support the principles and ambitions of TLCM as spelled out in the Defense Values for Acquisition which include:

- Recognize that people are the key to success

- Distinguish between the must haves, desirables and the nice to haves, if affordable.

- Identify trade offs between performance, time and cost.

- Never assume additional resources will be available

- Understand that delays cost

- Think incrementally to allow for change along the way and to use best practice.

- Quantify risk and reduce it by placing it where it can be managed most effectively.

- Recognize and respect the contribution made by Industry

- Value openness and transparency

- $\quad$ Embed a through life culture in all planning and decision making.

- Value objectivity based on clear evidence and learn from past experiences.

- $\quad$ People are held to account for their performance.

The comments, discussions and questions raised during the course, as well as discussions with representatives from industry and academia revealed that the TLCM initiative is regarded with a significant degree of skepticism by both sides of the defense community. Several comments were made about TLCM being replaced by some new initiative in five years' time. Lecturers and guest speakers on the course all emphasized that although the TLCM label will change, the underlying principles of TLCM will be carried forward in any new acquisition initiatives. 
The required rate of transition for the MoD is high. TLCM is expected to be fully implemented by 2012, by which time all the Mood's planning processes will be aligned to this paradigm.

\section{Discussion}

As with all models of complex systems, the model does not capture the "truth" about the TLCM enterprise, only a limited aspect of it and, with the TLCM concept evolving as it is being implemented in practice, the structures and interactions are expected to change. However, the model highlights challenges that will need to be addressed if TLCM, and capability management, is to be realized in the form currently being proposed.

First, as mentioned above, the model does not depict the many interactions between the different CPGs, CMGs, program boards, delivery teams, DLoDs and the industrial partners, because including them would make the model too unclear. However, the effectiveness and smoothness with which these interactions take place is essential for the success of the TLCM endeavor. This will depend greatly on the extent to which the individuals involved understand their role and contribution to the TLCM enterprise as a whole, as this will influence the extent and the way in which they share, access and process information. The reserve with which TLCM is perceived within the defense community seems to indicate that this insight is not as widely spread as may be required.

Second, the success of TLCM also depends on the degree of trust between the organizations as well as the individuals involved both between industry and the MoD as well as within the MoD and industry sectors respectively. This is of particular importance if the MoD is to engage with industry early in the capability planning stages. That is to say that capability will be enhanced through effective interactions between the supply chain organizations [28].

Third, the cross-DLoD approach to capability delivery challenges many people involved in TLCM. Moving from an equipment focused approach to acquisition, to one that requires all the lines of development to be given equal consideration as applicable, requires a new way of reasoning that can be described as systems thinking or systems awareness which, as discussed in the earlier part of this paper, in many ways is the opposite of an hierarchical, linear approach which characterizes the military organization as a whole. It also increases the amount of information that those responsible for planning, management, and bringing all the DLoDs together, need to process and "keep in their heads" - both in the MoD and in industry. From this perspective, the observed trend toward a "stovepipe" approach to capability acquisition management described above could be interpreted as an attempt by engineers and managers to simplify, albeit inappropriately, an increasingly complex information and organizational context.

Fourth, as a complex system, TLCM will never be finished and so the enterprise will be constantly evolving. The TLCM enterprise is a distributed knowledge system; not only do the organizations and individuals involved need process more interactions, they must also actively and continuously scan the enterprise to identify and locate new knowledge within it to inform and improve decision making, thereby contributing to even more interactions and feedback loops.

Fifth, TLCM involves a change in the fundamental concepts involved in acquisition. The grouping together of the MoD and industry as collaborative suppliers of capability is culturally challenging to those used to a more traditional customer-supplier terms. Both the Government/top level command and the soldier, sailor, aircrew are end-users of capabilities, but they are end users of very different levels of abstraction of capability. The collaborative nature of capability generation between Government and industry has both similarities and stark differences at these different levels.

Finally, the output from TLCM is improved management of capability through life. It is undeniable that the cross-capability and cross DLoDs approach to capability acquisition and the associated integrated supply chain involves major technical and engineering challenges that must be managed in a comprehensive and coordinated manner. TLCM aims to deliver this integrated approach to capability management

The enterprise mapping of TLCM reported above has indicated the complexity of the emerging MoD-industry relationship. In many ways this has raised more questions (enumerated above) than it has answered. The next stage of this research will be to focus more particularly on the interrelationships generated by the TLCM concept in order to understand more fully the impact on the acquisition processes.

\section{References}

[1] UK Ministry of Defense (MoD), "Defence Industrial Strategy, Defence White paper," Cm 6697, 2005. http://www.mod.uk/NR/rdonlyres/F530ED6C-F80C-4F24$\underline{8438-}$ 0B587CC4BF4D/0/def industrial strategy wp cm6697.pdf

[2] T. S. Baines, H. W. Lightfoot, S. Evans, et al., "Stateof-the-Art in Product-Service Systems," Journal of Engineering Manufacture, Part B, Vol 221, No. 10, pp. 1543-1552, 2007.

[3] H. Gebauer and T. Friedli, "Behavioral Implication of the Transition Process from Products to Services," Journal 
of Business \& Industrial Marketing, Vol 20, pp. 70-7, 2005.

[4] S. Johnstone, A. Dainty and A. Wilkinson, "Integrating Products and Services Through Life: an Aerospace Experience," International Journal of Operations \& Production Management, Vol 29, pp. 520537, 2008.

[5] R. Oliva and R. Kallenberg, "Managing the Transition from Products to Services," International Journal of Service Industry Management, Vol 14, pp. 160-171, 2003.

[6] R. Wise,. and P. Baumgartner, "Go Downstream The New Profit Imperative in Manufacturing". Harvard Business Review, Vol 77, No. 5, pp. 133-141, 1999.

[7] E. Molloy, C. E. Siemieniuch and M. A. Sinclair, "Decision-Making Systems and the Product-to-Service Shift," Journal of Manufacturing Technology Management, Vol 20, pp. 606-625, 2009.

[8] M. A. Sinclair, M. J. d. Henshaw, R. A. Haslam, C. E. Siemieniuch, J. L. Evans and E. Molloy, "Governance, Agility and Wisdom in the Capability Paradigm," in Contemporary Ergonomics 2009, Philip D. Bust, Ed. Taylor \& Francis, London, 2009, pp 100-110.

[9] P. Ito, "Through Life Capability Management Practitioners Course," Defence Academy of the United Kingdom, 2009.

[10] E. Urwin, S. Ahlberg Pilfold and M. Henshaw, "Through Life Capability Management: Benefits and Behaviours,", in Contemporary Ergonomics and Human Factors 2010, ed. Martin Anderson, CRC Press, London, 2010.

[11] UK Ministry of Defense (MoD). Acquisition Operation Framework. Version 2.0.17, October 2009. http://www.aof.mod.uk/

[12] P. Cilliers, "Knowing Complex Systems," in Managing Organisational Complexity - Philosophy, Theory, Application, K. A. Richardson, Ed. Greenwich, CT, Information Age Publishing, 2005, pp. 7-12.

[13] P. Cilliers, "Boundaries, Hierarchies and Networks in Complex Systems," International Journal of Innovation Management, Vol 5, No. 2, pp. 135-147.

[14] F. A. Hayek, "The Use of Knowledge in Society," American Economic Review, Vol 35, pp. 519-530, 1945.

[15] S. Turnbull, "The Use of Bytes to Analyze Complex Organizations", in Managing Organisational Complexity Philosophy, Theory, Application, K. A. Richardson, Ed.
Greenwich, CT, Information Age Publishing, 2005, pp. 151-164

[16] K. Baker, "Where Will Knowledge Management Take Us?" in Knowledge Management and Organizational Memories ,1st ed. R. Dieng-Kuntz and N. Matta, Eds. Norwell, MA, Kluwer Academic Publishers, 2002, pp. 312.

[17] T. H. Davenport and L. Prusak, Working with Knowledge: How Organisations Manage What They Know, Boston, MA, Harvard Business School Press, 1998,

[18] T. Kalling and A. Styhre, Knowledge Sharing in Organisations, Malmö: Liber AB, 2003,

[19] S. Newell, M. Robertson, H. Scarbrough and J. Swan, Managing Knowledge Work, Basingstoke, Palgrave Macmillan, 2002,

[20] A. Jashapara, Knowledge Management - an Integrated Approach, Harlow, Financial Times Prentice Hall, 2004.

[21] I. Nonaka, The Knowledge-Creating Company, Boston, MA, Harvard Business School Publishing Corporation, 2008,

[22] H. Tsoukas, The Firm as a Distributed Knowledge System: A Constructionist Approach, Strategic Management Journal, Vol 17, pp. 11-26, 1996.

[23] M. Polanyi, The Tacit Dimension, New York, NY, Anchor Day Books, 1966.

[24] F. Blackler, "Knowledge, Knowledge Work, and Organizations: an Overview and Interpretation," Organization Studies, Vol 16, pp. 1021-1046, 1995.

[25] H. Collins, "The Structure of Knowledge," Social Research, Vol 60, pp. 95-116, 1993.

[26] K. Eason, S. Harker and W. Olphert, "Working with Users to Generate Organisational Requirements: The ORDIT Methodology," ICL Systems Journal, Vol 11, pp. 205-220, 1997.

[27] K. Eason, S. Harker and W. Olphert, "Representing Socio-technical Systems Options in the Development of New Forms of Work Organization," European Journal of Work and Organizational Psychology, Vol 5, pp. 399-419, 1996.

[28] S. Croom, S. and J. Batchelor, "The development of Strategic Capabilities - an Interaction View”, Integrated Manufacturing Systems, vol 8, No. 5, pp. 299-312, 1997. 